\title{
Myo-inositol increases the plating efficiency of protoplast derived from cotyledon of cabbage (Brassica oleracea var. capitata)
}

\author{
Eun Yee Jie - Suk Weon Kim · Hye Rim Jang - Dong Su In - Jang Ryol Liu
}

Received: 7 March 2011 / Accepted: 17 March 2011

(c) Korean Society for Plant Biotechnology

\begin{abstract}
This study describes the effect of myo-inositol on sustained cell division and plant regeneration from cotyledon-derived protoplast of cabbage (Brassica oleracea var. capitata). Freshly isolated protoplasts were cultured in modified Murashige and Skoog (MS) medium removed ammonia ions and containing $0.4 \mathrm{mg} \mathrm{l}^{-1}$ thiamine $\cdot \mathrm{HCl}, 100$ $\mathrm{mg}^{-1}$ myo-inositol, $2 \mathrm{mgl}^{-1}$ 2,4-D, $0.5 \mathrm{mgl}^{-1} \mathrm{BA}, 30 \mathrm{gl}^{-1}$ sucrose and several concentrations of myo-inositol (2, 4, 6 , $8,10 \%(\mathrm{w} / \mathrm{v}))$ as an osmotic stabilizer. After 3 weeks of culture in the dark at $25^{\circ} \mathrm{C}$, the plating efficiency of cabbage protoplasts reached to $22.5 \pm 2.9 \%$ when cultured in modified MS medium supplemented with $2 \mathrm{mgl}^{-1}$ 2,4-D, $0.5 \mathrm{mgl}^{-1} \mathrm{BA}$, $30 \mathrm{gl}^{-1}$ sucrose and $8 \%(\mathrm{w} / \mathrm{v})$ of myo-inositol at a density of $2 \times 10^{5}$ protoplasts $/ \mathrm{ml}$. Rapidly growing cell colonies after 3 weeks of culture were transferred to the same culture medium removed osmoticum. To induce shoot regeneration from calluses, calluses with about $2 \mathrm{~mm}$ in diameter were transferred to the MS medium containing $2 \mathrm{mgl}^{-1} \mathrm{BA}$ and 0.5 $\mathrm{mgl}^{-1}$ NAA. After further three weeks of incubation onto the medium in the light, green shoots were formed on the surface of calluses at a frequency of $30 \%$. Upon transfer to half-strength MS basal medium, roots were formed onto the bottom of regenerated shoots without auxin treatments. These regenerated plantlets were successfully acclimatized to soil transfer, grown to normal mature plants. The cabbage protoplast culture system established in this study could be applied for production of somatic hybrids or cybrids by
\end{abstract}

\footnotetext{
E. Y. Jie $\cdot$ H. R. Jang $\cdot$ J. R. Liu ( ()

Plant Systems Engineering Research Center, Korea Research Institute of Bioscience and Biotechnology (KRIBB), 125 Gwahak-ro, Yuseong-gu, Daejeon 305-806, South Korea e-mail: jrliu@kribb.re.kr

S. W. Kim

Biological Resources Center, Korea Research Institute of Bioscience and Biotechnology (KRIBB), 125 Gwahak-ro, Yuseong-gu, Daejeon 305-806, South Korea

D. S. In

Department of Biology, KongJu University, Korea
}

asymmetric protoplast fusion and mass proliferation of elite somatic clones of cabbage.

Keywords Cabbage (Brassica oleracea var. capitata) - Protoplast culture - Plant regeneration

\begin{abstract}
Abbreviations 2,4-D: 2,4-dichlorophenoxyacetic acid; BA: 6-benzyladenine; CPW: Cell Protoplasts Washing; MS: Murashige and Skoog; NAA: a-naphthaleneacetic acid
\end{abstract}

\section{Introduction}

Brassica including broccoli, cabbage, rapeseed, and mustard is valuable vegetables and oil crops belonging to the Cruciferae. In Europe, the predominance goes to $B$. oleracea, a species that includes important crops such as cabbage, broccoli, cauliflower etc. Whereas, B. campestris is the most cultivated species owing to the great importance of Chinese cabbage in Asia. The vegetables have been very important in Korea as a major farmers' income source being $29 \%$ of their total farming income, and as indispensable component of their diet for many years. Korean seed market for Chinese cabbage, radish and cabbage was $\$ 12.02, \$ 25.54$ and $\$ 1.12$ million respectively in 2003 (Park 2006).

Breeding strategy and targets are perfectly dependent on market trends. With an increasing number of consumers aware of the importance of diet on human health, vegetable brassicas have new appeal as a diet food with green vegetables during recent years. However, without having new genetic resources that contain horticulturally important characters, it is very difficult to develop a new vegetable variety by crossing or conventional breeding. Asymmetric cell fusion technology is to combine two cells by protoplast culture with electrical shock or PEG or radiation. 
This technique is very powerful because it generates a new crop or mutant by mixing the different genomes and ends up with a new genetic source. This technology would expand the breeding program of Cruciferae with the new CMS character (Monteiro and Lunn 1999)

Since the first successful plant regeneration from mesophyll protoplasts of rape plants (Kartha et al. 1974), lots of studies has been reported in protoplast culture and plant regeneration of the genus, Brassica. Li and Kohlenbach (1982) reported that plant regeneration was possible directly from mesophyll protoplast culture of Brassica napus via direct somatic embryogenesis. Successful plant regeneration was also established in cauliflower from various protoplast cultures including cotyledon (Vatsya and Bhaskaran 1982), root (Xu et al. 1982) and leaf explants (Bidney et al. 1983; Fu et al. 1985) of Brassica. Effects of media components and environmental factors on growth and organogenesis of protoplast-derived calli were also investigated (Lillo and Olsen 1989). Recently, protocol for rapid and efficient plant regeneration from protoplasts of cabbage was developed by a novel nurse culture method (Chen et al. 2004) and shoot cultures in large glass vessels with vented lids (Chikkala et al. 2009). A lot of successful studies are also reported from protoplast culture of Brassica for somatic cell hybridization. Gleba and Hoffmann (1978, 1979) produced Arabido-brassica, intergeneric hybrids, by protoplast fusion between Arabidopsis thaliana and $B$. campestris. Until now, several Brassica oleracea hybrids have been created through somatic cell hybridization between B. oleracea and other plants (Schenck and Hoffmann 1979; Hansen and Earle 1997; Ishikiwa et al. 2003; Motegi et al. 2003; Yamagishi and Nakagawa 2004; Chen et al. 2005). Thus, the techniques of protoplast culture and asymmetric protoplast fusion have provided a new way for quality improvement in Brassica species. Although techniques for protoplast culture of cabbage have advanced in some ways in recent years, there is still demand for further improvement in such areas as the choice of donor plant materials with agricultural characteristics, the optimization of culture medium and culture conditions. The present paper reports on the callus formation and plant regeneration from cotyledon- derived protoplasts of cabbage using myo-inositol as an osmotic stabilizer.

\section{Materials and methods}

Plant materials

The cabbage (Brassica oleracea var. capitata cv. 'Dongbok') seeds used in this study were purchased from Nong Woo Bio (Co.). This cultivar has been widely used in cabbage production in Korea. Seeds were surface sterilized in $70 \%$ alcohol for $3 \mathrm{~min}$, soaked in a sodium hypochloride solution containing $1 \%$ active chloride for $15 \mathrm{~min}$ then washed 3 times with sterilized distilled water. Seeds were transferred onto the Murasige and Skoog (Murashige and Skoog 1962) MS medium containing $0.4 \mathrm{mg} \mathrm{l}^{-1}$ thiamine. $\mathrm{HCl}, 100 \mathrm{mg} \mathrm{l}^{-1}$ myo-inositol, $30 \mathrm{~g} \mathrm{l}^{-1}$ sucrose and plant agar $8 \mathrm{~g} \mathrm{l}^{-1}, \mathrm{pH} 5.8$ (adjusted before autoclaving). Seed germination and seedling growth was maintained a tissue culture room at $25^{\circ} \mathrm{C}$ under 16 -h photoperiod. The cotyledon $3 \sim 7$ days after sowing were used for protoplast isolation.

\section{Protoplast isolation}

Cotyledon of one week old seedlings (approximately $1 \mathrm{~g}$ in fresh weight) were harvested and incubated overnight with $10 \mathrm{ml}$ of an enzyme solution in an $100 \times 20 \mathrm{~mm}$ plastic Petri dish on a gyratory shaker $(30 \mathrm{rpm})$ at $25^{\circ} \mathrm{C}$ in the dark. For improving cell wall digestion, each cotyledon were cut into $1 \sim 2 \mathrm{~mm}$ thick and soaked in a plasmolytic solution i.e. $13 \%$ mannitol CPW solution (Frearson et al. 1973) for 30 min which was replaced by the enzyme mixture. The enzyme solution consisted of cellulase and pectinase (Novozymes) mixture, $3 \mathrm{mM}$ MES (2-[N-Morpholino] ethanesulfonic acid), and 9\% mannitol in CPW (Frearson et al. 1973) salts. The enzyme solution was filter-sterilized through a $0.22 \mu \mathrm{m}$ nylon membrane and $\mathrm{pH}$ adjusted to 5.8 with $1 \mathrm{~N} \mathrm{NaOH}$. After incubation the protoplasts were purified by passing the digested cell aggregates in the enzyme solution through 250 and $50 \mu \mathrm{m}$ stainless steel mesh screens in a plastic Petri dish. The enzyme solution containing protoplasts was transferred to a $15 \mathrm{ml}$ Falcon centrifuge tube and spun at $100 \mathrm{Xg}$ for $5 \mathrm{~min}$. After removal of the enzyme solution with a Pasteur pipette, protoplasts packed at the bottom of the tube were resuspended in CPW solution containing 9\% mannitol. The protoplast washing (centrifugation/resuspension) process was repeated three times. The final protoplast purification step using CPW containing $21 \%$ sucrose to float protoplasts was omitted. The protoplasts were collected with a Pasteur pipette and finally resuspended in $10 \mathrm{ml}$ of modified MS medium fully removed ammonia ions and containing $0.4 \mathrm{mg} \mathrm{l}^{-1}$ thiamine $\cdot \mathrm{HCl}, 60 \mathrm{gl}^{-1}$ myo-inositol, $30 \mathrm{gl}^{-1}$ sucrose, $2 \mathrm{mgl}^{-1}, 2,4-\mathrm{D}$ and $0.5 \mathrm{mgl}^{-1} \mathrm{BA}$ at $\mathrm{pH} 5.8$ (initial protoplast culture medium). The density and the total yield of protoplasts were estimated using a hemocytometer and then adjusted to adequate protoplast densities of $2 \times 10^{5}, 1 \times 10^{5}$, and $5 \times 10^{4}$ protoplasts $/ \mathrm{ml}$ for 
culture. After density adjustment, the protoplasts cultures were kept in $60 \times 15 \mathrm{~mm}$ Petri dish (Falcon, 3002 tissue culture dish) at $25^{\circ} \mathrm{C}$ in the dark.

Protoplast culture

One $\mathrm{ml}$ of protoplast suspension was plated on a plastic Petri dish (Falcon, $60 \times 15 \mathrm{~mm}$ ) as a thin layer liquid culture. Also the protoplasts were incubated by agarose embedding culture. One $\mathrm{ml}$ of protoplast suspension and same volume of protoplast culture medium with $1.2 \%$ agarose typeVII (Sigma, USA) at $40^{\circ} \mathrm{C}$ was mixed to a plastic Petri dish (Falcon, 60 x $15 \mathrm{~mm}$ ) (agarose embedding culture). Protoplasts were incubated at $25^{\circ} \mathrm{C}$ in the dark and cell division was periodically observed with an inverted microscope. To induce sustained cell division, the initial protoplast culture medium was replaced with modified protoplast culture medium containing $20.6 \mathrm{mM}$ ammonia $\left(\mathrm{NH}_{4}{ }^{+}\right), 39.4 \mathrm{mM}$ nitrate ions $\left(\mathrm{NO}_{3}{ }^{-}\right)$of the original MS salts after two weeks of culture. The plating efficiency ( $\%$ of plated protoplasts which divided at least once) was determined after 3 weeks culture. Cell colonies seen with the naked eye in liquid or agarose embedding culture were then transferred onto a agar-solidified ( $0.4 \%$ Gelrite) protoplast culture medium supplemented with varying combinations of growth regulators in order to proliferate callus growth and induction of shoot organogenesis.

Effect of plant growth regulators and myo-inositol concentration on plating efficiency of cabbage protoplast

The effect of plant growth regulators on plating efficiency was examined. Freshly isolated protoplasts were diluted using initial protoplast culture medium at density of $1 \times 10^{5}$ protoplasts $/ \mathrm{ml}$. Each 200 ul of protoplast suspension without no plant growth regulators was dispensed into 24 well plate and then filter-sterilized 2,4-D and BA were add to each well. The final concentration of 2,4-D and BA was adjusted to $0,0.1,0.3,1,3$ and $10 \mathrm{mg} \mathrm{l}^{-1}$ respectively. Several combinational treatment of 2,4-D and BA was also examined (Table 1). Furthermore, we also investigated the effect of myo-inositol on plating efficiency, the final concentration of myo-inositol in initial protoplast culture medium was adjusted to $20,40,60,80$ and $100 \mathrm{gl}^{-1}$ respectively. In order to examine the effect of myo-inositol on plating efficiency, protoplasts were also resuspended in an initial protoplast culture medium in which myo-inositol was replaced with $90 \mathrm{~g} \mathrm{l}^{-1}$ mannitol. All protoplasts cultures were kept in $60 \times 15 \mathrm{~mm}$ Petri dish at $25^{\circ} \mathrm{C}$ in the dark. The plating efficiency ( $\%$ of plated protoplasts which divided at least once) from all treatments was determined after three weeks culture. All treatments consisted with three replicates for statistical analysis.

Plant regeneration from protoplast-derived callus of cabbage

To induce sustained callus growth, cell colonies seen with the naked eye in liquid or agarose embedding culture were then transferred onto MS medium containing $2 \mathrm{mg}^{-1}$ 2,4-D and $0.5 \mathrm{mg} \mathrm{l}^{-1} \mathrm{BA}$. After two weeks of cultures, microcalluses were transferred to MS medium supplemented with $2 \mathrm{mg}^{-1} \mathrm{BA}$ and $0.5 \mathrm{mg} \mathrm{l}^{-1} \mathrm{NAA}$ in order to proliferate callus growth and induction of shoot organogenesis. Also we examined the effect of gelling agent ( $0.4 \%$ Gelrite and $0.8 \%$ Plant agar) on shoot formation from callus during the culture. These cultures were maintained at $25^{\circ} \mathrm{C}$ in the light (approximately $30 \mu \mathrm{mol} \mathrm{m} \mathrm{s}^{-2}$ from cool-white fluorescent lamps with a 16-h photoperiod). The efficiency of shoot formation from protoplastderived calluses was determined after 3 weeks culture. All treatments consisted with three replicates for statistical analysis. To regenerate whole plants, green shoots formed on calluses derived from protoplasts were transferred to MS basal medium and cultured in the light (approximately $30 \mu \mathrm{mol} \mathrm{m} \mathrm{m}^{-2}$ from cool-white fluorescent lamps with a 16-h photoperiod). After 4 weeks of incubating in the light, regenerated plantlets with rooting were transplanted into potting soil (vermiculite:perlite, 3:1 mixture) and maintained in plastic container for two weeks. After emergence of new leaves from transplanted plants, acclimatized plants were transferred and maintained in a growth chamber $(80 \mu$ $\mathrm{mol} \mathrm{m} \mathrm{m}^{-2}$ from cool-white fluorescent lamps with a $16-\mathrm{h}$ photoperiod and $50 \sim 70 \% \mathrm{RH}$ ).

\section{Statistical analysis}

The experiment was conducted in a completely randomized design with three replicates. Data were subjected to an analysis of variance (ANOVA). To determine the significant difference in mean ranges, one way ANOVA was performed using Origin software (Ver. 8; OriginLab Co, USA).

\section{Results and discussion}

Isolation and culture of cotyledon-derived protoplasts of cabbage 
Large quantities of viable protoplasts could be obtained from cotyledon of cabbage seedlings after enzymatic digestion (Fig. 1A). The diameter of freshly isolated protoplasts was $20 \sim 50 \mu \mathrm{m}$ (Fig. 1A). After 3 to 5 days of culture, protoplasts underwent first cell division (Fig. 1B). After 1 week of culture, second cell division occurred at a frequency of approximately $30 \%$ (Fig. 1C). Cell colonies reached a diameter of $100 \sim 200 \mu \mathrm{m}$ after 3 weeks of culture (Fig. 1D), and after 4 weeks of culture, numerous microcalluses were formed (Fig. 1E). We examined the adequate protoplast densities for prototoplast division and plant regeneration. The highest plating efficiency (about 17\%) was obtained when they cultured into the initial protoplast medium at densities of $2 \times 10^{5}$ (Fig. 2). However when protoplasts cultured at a density $1 \times 10^{5}$ and $5 \times 10^{4}$, the cell division efficiency was decreased to 13 to $10 \%$. Over than $2 \times 10^{5}$ treatment, exact examination of cell division efficiency was difficult too numerous cells to count. Therefore, an optimal prototoplast density for protoplast culture was found to be the treatment of 1 to $2 \times 10^{5}$ from cotyledon-derived protoplast of cabbage.

In the preliminary studies, initial protoplast culture medium without free ammonia ions was suitable for sustained cell division. However, cell colonies showed browning and eventually dead after three weeks of culture. To induce sustained cell division, the initial protoplast culture medium was replaced with modified protoplast culture medium containing $20.6 \mathrm{mM}$ ammonia $\left(\mathrm{NH}_{4}{ }^{+}\right), 39.4 \mathrm{mM}$ nitrate
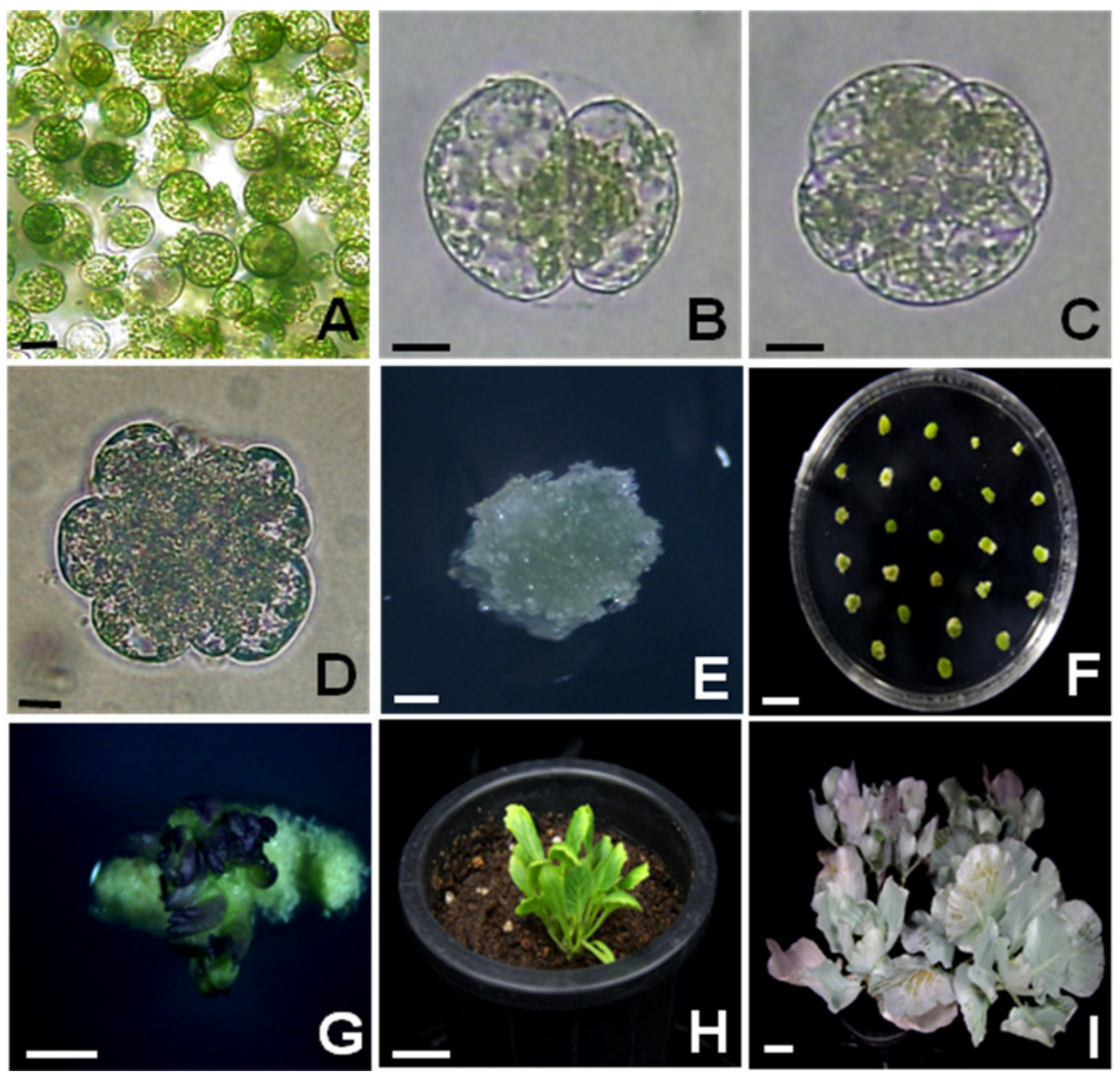

Fig. 1 Plant regeneration from cotyledon-derived protoplast culture of cabbage. A: Freshly isolated protoplasts; B: First cell division in cultured protoplasts after 3 to 5 days of culture; C: Second cell division in cultured protoplasts after 1 week of culture; D: Cell colony formation in cultured protoplasts after 4 to 6 weeks of culture; E: Microcallus formation in cultured protoplasts after 8 weeks of culture; F: Shoot induction from microcallus; G: Shoot formation from microcallus; H: Soil transfer of regenerated plantlet; I: Regenerated plantlets from protoplast-derived calluses via shoot organogenesis. Scale bars represent $20 \mu \mathrm{m}(\mathrm{A} \sim \mathrm{D}), 1 \mathrm{~mm}(\mathrm{E}), 1 \mathrm{~cm}$ $(\mathrm{F} \sim \mathrm{G})$ and $2 \mathrm{~cm}(\mathrm{H} \sim \mathrm{I})$ 


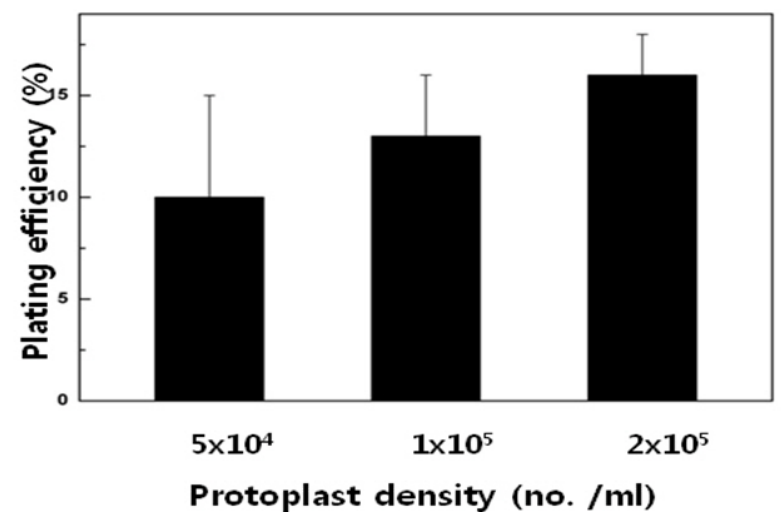

Fig. 2 Plating efficiency from cotyledon-derived protoplast culture of cabbage. Bars represent standard deviation. At the 0.01 level, the population means are significantly different $($ Prob $=$ $0.009459)$

ions $\left(\mathrm{NO}_{3}{ }^{-}\right)$of the original MS salts after two weeks of culture. Cell colonies from protoplast could be maintained and proliferated on a modified protoplast culture medium.

Effect of growth regulators on cell division of cabbage protoplast

We examined the optimal plant growth regulators for sustained cell division from cotyledon-derived protoplast of cabbage (Table 1). The highest plating efficiency was obtained when protoplasts were cultured onto initial protoplast culture medium containing $3 \mathrm{mgl}^{-1}$ 2,4-D and 0.5 $\mathrm{mgl}^{-1}$ BA. No cell division and cell colony formation occurred in 2,4-D or BA alone treatments. Cell divisions were observed in combinational treatment of 2,4-D and BA. Cell division frequency was increased in high molar ratio of 2,4-D to BA (2,4-D/BA), whereas division frequency was decreased in low molar ratio of 2,4-D to BA.
These results indicated that high concentration of 2,4-D and low concentration of BA stimulate cell division from cotyledon-derived protoplast of cabbage simultaneously. Similar results were also shown in agarose embedding cultures (data not shown). Therefore we concluded that optimal plant growth regulators for cabbage protoplast culture was 1-to $3 \mathrm{mgl}^{-1}$ 2,4-D and $0.5 \mathrm{mgl}^{-1} \mathrm{BA}$. These culture conditions were used following experiments.

Effect of myo-inositol on plating efficiency of cabbage protoplast

In an initial experiment, several concentrations of osmoticum in the initial protoplast culture medium containing myoinositol 20, 40, 60, 80 and $100 \mathrm{gl}^{-1}$ respectively were examined (Fig. 3). The plating efficiency was 15, 21.5 and $22.5 \%$ when cultured the medium containing 40,60 , and $80 \mathrm{gl}^{-1}$ myo-inositol, respectively. The highest plating efficiency was obtained when protoplasts were cultured into the medium containing $80 \mathrm{gl}^{-1}$ myo-inositol. The plating efficiency was slightly decreased to $20.1 \%$ when protoplasts were cultured into the medium containing 100 $\mathrm{gl}^{-1}$ myo-inositol. However, no cell divisions and cell colony formation occurred in case of $20 \mathrm{gl}^{-1}$ treatment. These results showed that optimal concentration of myoinositol for osmotic stabilizer was 60 to $100 \mathrm{gl}^{-1}$. These results were unchanged regardless of modification of protoplast densities (Fig. 3). We also compared the effect of myo-inositol and mannitiol on plating efficiency (Fig. 4). The plating efficiency was decreased when protoplasts were cultured in the medium containing $9 \%$ mannitol instead of $6 \%$ myo-inositol. These results showed that myo-inositol might be more suitable osmotic stabilizer for sustained cell division from cotyledon-derived protoplast

Table 1 Effect of plant growth regulators on cell division from cotyledon-derived protoplast cultures of cabbage

\begin{tabular}{|c|c|c|c|c|c|c|}
\hline \multirow{2}{*}{$\begin{array}{l}\text { Plant growth } \\
\text { regulators }\end{array}$} & \multicolumn{6}{|c|}{ Concentration of Plant growth regulators $\left(\mathrm{mg} \mathrm{l}^{-1}\right)$} \\
\hline & \multicolumn{6}{|c|}{ Plating efficiency $*$} \\
\hline \multirow{2}{*}{$2,4-\mathrm{D}$} & 0 & 0.1 & 0.3 & 1 & 3 & 10 \\
\hline & - & - & - & - & - & - \\
\hline \multirow{2}{*}{ BA } & 0 & 0.1 & 0.3 & 1 & 3 & 10 \\
\hline & - & - & - & - & - & - \\
\hline \multirow{2}{*}{$2,4-\mathrm{D}+\mathrm{BA}$} & $1+0.1$ & $1+0.3$ & $1+0.5$ & $1+1$ & $1+3$ & $1+10$ \\
\hline & - & + & + & + & + & - \\
\hline \multirow{2}{*}{$2,4-\mathrm{D}+\mathrm{BA}$} & $3+0.1$ & $3+0.3$ & $3+0.5$ & $3+1$ & $3+3$ & $3+5$ \\
\hline & + & ++ & +++ & + & + & + \\
\hline
\end{tabular}

*Plating efficiency was determined after two weeks of culture.

$-/+$ symbols represent the frequency of cell division 


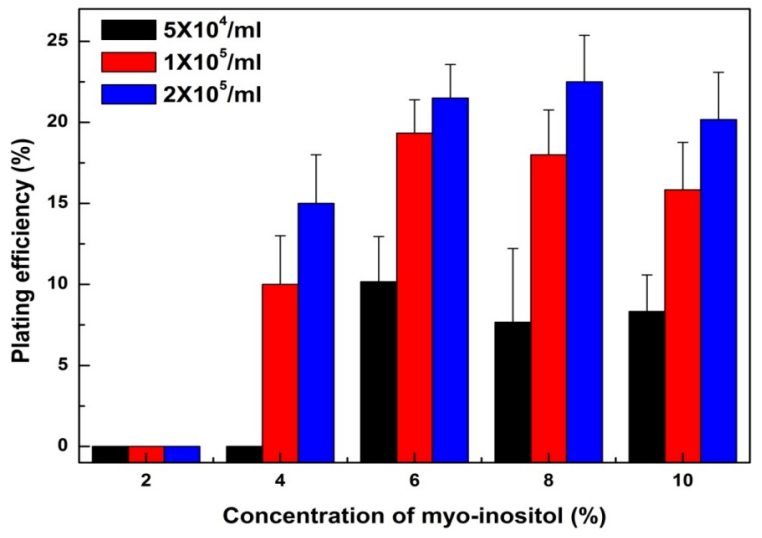

Fig. 3 Effect of myo-inositol concentration on plating efficiency from cotyledon-derived protoplast from cabbage. Vertical bars represent standard deviation. At the 0.001 level, the population means are significantly different $(\mathrm{Prob}=2.229 \mathrm{E}-7)$

of cabbage. This result is in agreement with Arya et al. (1991) who reported that myo-inositol worked as an osmotic stabilizer for sustained division of ginseng protoplasts. Myo-inositol play a role as precursors to many compounds whose function in plants is linked to phosphorus storage, signal transduction, stress protection, hormonal homeostasis and cell wall biosynthesis (Hegeman et al. 2001). Myo-inositol is also considered as a growth enhancer in vitro and may be a carbohydrate source, which are good osmoticum for protoplast isolation (Azad et al. 2006). Myo-inositol oxidation pathway has a predominant role in the biosynthesis of new cell walls of the hypocotyl and roots in germinating beans (Sasaki et al. 1989). Recently, Abid et al. (2009) reported that myo-inositol phosphate synthase (MIPS), which catalyses the first step in inositol biosynthesis are involved in various physiological processes including embryogenesis, seedling growth and resistance to biotic and abiotic stresses. Previously we also reported that myo-inositol was a more efficient osmotic stabilizer for sustained cell division from protoplast cultures of $R$. hybrida (Kim et al. 2003). Furthermore, myo-inositol was used for protoplast cultures as an osmoticum including Lycopersicon esculentum (Bellini et al. 1990), Picea Glauca (Attree et al. 1989). Cell wall regeneration and resistance to abiotic stresses are necessarily required processes for successful cell division and proliferation from protoplast culture. Therefore, we inferred that application of myo-inositiol as an osmotic stabilizer in protoplast culture could have advantages not only carbohydrate metabolisms in cell walls but also inositol metabolisms in cell membrane. Considering these results we suggested that myo-inositol might be more suitable osmotic stabilizer for sustained cell division from

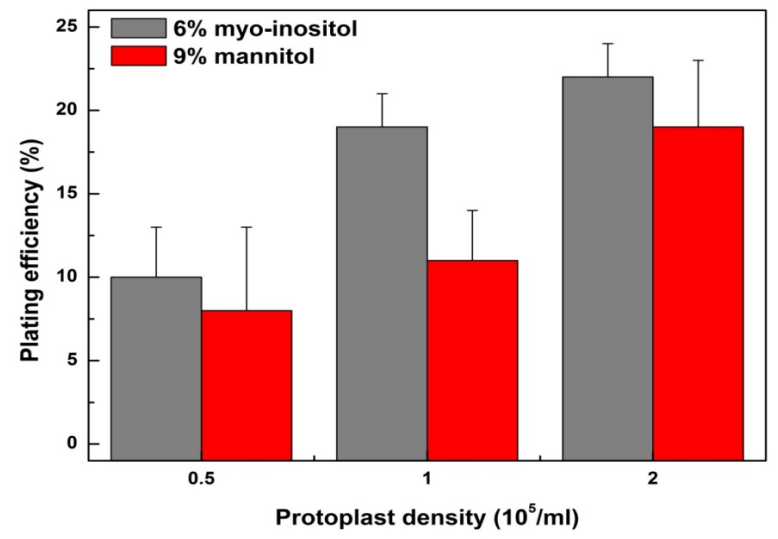

Fig. 4 Effect of osmoticums (6\% myo-inositol and 9\% mannitol) on plating efficiency from cotyledon-derived protoplast from cabbage. Vertical bars represent SD. At the 0.001 level, the population means are significantly different $($ Prob $=9.488 \mathrm{E}-5)$

protoplast culture.

Plant regeneration from protoplast cultures of cabbage

Callus proliferated on modified protoplast culture medium were transferred to shoot differentiation medium supplemented with several concentrations $2 \mathrm{mgl}^{-1} \mathrm{BA}$ and 0.5 $\mathrm{mgl}^{-1}$ NAA (Fig. 1F). After four weeks of culture, green and reddish shoot primordia were formed on the surface of callus when cultured in the light (Fig. 1G). Upon transfer to half-strength MS basal medium, roots were formed onto the bottom of shoots without auxin treatments (Fig. 1H). These regenerated plantlets were successfully acclimatized to soil transfer, grown to normal mature plants (Fig. 1I). In the preliminary study, we determined the optimal growth regulators conditions for shoot differentiation from cotyledon explants of cabbage. The highest frequency of shoot differentiation from cotyledon explants of cabbage was $80 \%$ when they cultured onto MS medium $2 \mathrm{mgl}^{-1} \mathrm{BA}$ and $0.5 \mathrm{mgl}^{-1} \mathrm{NAA}$. Also we examined the effect of gelling agent $(0.4 \%$ Gelrite and $0.8 \%$ Plant agar) on shoot formation from callus during the culture. The efficiency of shoot formation from $0.4 \%$ Gelrite treatment was $2 \sim 3$ times higher than that of $0.8 \%$ Plant agar (Fig. 5). Shoot differentiation could be achieved from protoplast-derived callus of cabbage when cultured on same medium used for shoot differentiation from cotyledon explants. About 30\% of protoplast-derived callus formed shoots when they cultured onto MS medium containing $2 \mathrm{mgl}^{-1} \mathrm{BA}$ and 0.5 $\mathrm{mgl}^{-1}$ NAA.

Culture conditions for high frequency plant regeneration from cotyledon-derived protoplasts in cabbage were determined in this study. Also we found that myo-inositol was 


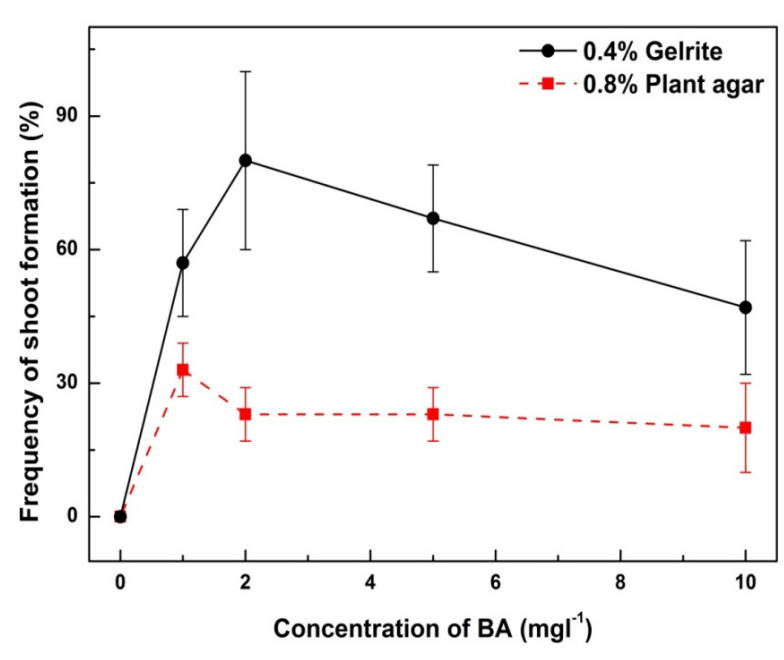

Fig. 5 Effect of BA on shoot formation from cotyledon explants cultures of cabbage. vertical bars represent SD

more efficient osmotic stabilizer for sustained cell division of cabbage protoplast than mannitol. Therefore, this plant regeneration system from protoplasts of cabbage could be applied for somatic hybridization and direct gene transfer in quality improvement of cabbage cultivars.

\section{Acknowlmentedge}

This work was supported by a grant (AGC1100912) to JRL from the Korean Ministry for Food, Agriculture, Forestry and Fisheries, a grant to JRL from the Crop Functional Genomics Center of the $21^{\text {st }}$ Century Frontier Research Program funded by the Korea Ministry of Education, Science and Technology, a grant to JRL from the Marine Extreme Genome Research Center funded by the Korean Ministry of Marine Affairs.

\section{References}

Abid G, Silue S, Muhovski Y, Jacquemin JM, Toussaint A, Baudoin JP (2009) Role of myo-inositol phosphate synthase and sucrose synthase genes in plant seed development. Gene 439:1-10

Arya S, Liu JR, Eriksson T (1991) Plant regeneration from protoplast of Panax ginseng (CA Meyer) through somatic embryogenesis. Plant Cell Rep 10:277-281

Attree SM, Dunstan DI, Fowke LC (1989) Plantlet Regeneration from Embryogenic Protoplasts of White Spruce (Picea Glauca). Nat Biotechnol 7:1060-1062

Azad MAK, Yokota S, Ishiguri F, Yoshizawa N, Saxena P (2006) Plant regeneration from mesophyll protoplasts of a medicinal plant, Phellodendron amurenserupr. In Vitro Cell Dev Biol
Plant 42:502-507

Bellini C, Chupeau MC, Gervais M, Vastra G, Chupeau Y (1990) Importance of myo-inositol, calcium, and ammonium for the viability and division of tomato (Lycopersicon esculentum) protoplasts. Plant Cell Tiss Organ Cult 23:27-37

Bidney DL, Shepard JF, Kaleikau E (1983) Regeneration of plants from mesophyll protoplasts of Brassica oleracea. Protoplasma 117:89-92

Chen LP, Zhang MF, Xiao QB, Wu JG, Hirata Y (2004) Plant regeneration from hypocotyl protoplasts of red cabbage (Brassica oleracea) by using nurse cultures. Plant Cell Tiss Organ Cult 77:133-138

Chen LP, Zhang MF, Li CS, Hirata Y (2005) Production of interspecific somatic hybrids between tuber mustard (Brassica juncea) and red cabbage (Brassica oleracea). Plant Cell Tiss Organ Cult 80:305-311

Chikkala VRN, Nugent GD, Dix PJ, Stevenson TW (2009) Regeneration from leaf explants and protoplasts of Brassica oleracea var. botrytis (cauliflower). Sci Hortic 119:330-334

Frearson EM, Power JB, Cocking EC (1973) The isolation, culture and regeneration of Petunia leaf protoplasts. Dev Biol 33:130-137

Fu YY, Jia SR, Lin Y (1985) Plant regeneration from mesophyll protoplast culture of cabbage (Brassica oleracea var 'capitata') Theor Appl Genet 71:495-499

Gleba YY, Hoffmann F (1978) Hybrid cell lines Arabidopsis thaliana+Brassica campestris asexual hybrid no evidence for specific chromosome elimination. Mol Gen Genet 165: 257-264

Gleba YY, Hoffmann F (1979) Arabidobrassica: Plantgenome engineering by protoplast fusion. Naturwissenschaften 66 : 547-554

Hansen LN, Earle ED (1997) Somatic hybrids between Brassica oleracea L. and Sinapis alba L. with resistance to Alternaria brassicae (Berk.) Sacc. Theor Appl Genet 94:1078-1085

Hegeman CE, Good LL, Grabau EA (2001) Expression of d-myo-inositol-3-phosphate synthase in soybean. Implication for phytic acid biosynthesis. Plant Physiol 125:1941-1948

Ishikawa S, Bang SW, Kaneko Y, Matsuzawa Y (2003) Production and characterization of intergeneric somatic hybrids between Moricandia arvensis and Brassica oleracea. Plant Breeding 122:233-238

Kartha KK, Michayluk MR, Kao KN, Gamborg OL, Constabel F (1974) Callus formation and plant regeneration from mesophyll protoplasts of rape plants Brassica napus cultivar Zephyr. Plant Sci Lett 3: 265-271

Kim SW, Oh SC, DS In, Liu JR (2003) Plant regeneration of rose (Rosa hybida L.) from embryogenic cell derived protoplasts. Plant Cell Tiss Organ Cult 73:15-19

Li LC, Kohlenbach HW (1982) Somatic embryogenesis in quite a direct way in cultures of mesophyll protoplasts of Brassica napus L. Plant Cell Rep 1:209-211

Lillo C, Olsen JE (1989) Growth and shoot formation in protoplastderived calli of Brassica oleracea ssp. acephala and ssp. capitata. Plant Cell Tiss Organ Cult 17:91-100 
Motegi T, Nou IS, Zhou J, Kanno A, Kameya T, Hirata Y (2003) Obtaining an ogura-type CMS line from asymmetrical protoplast fusion between cabbage (fertile) and radish (fertile). Euphytica 129:319-323

Monteiro A, Lunn T (1999) Trends and perspectives vegetable Brassica breeding world-wide. Acta Hort (ISHS) 495:273-280

Murashige T, Skoog F (1962) A revised medium for rapid growth and bioassays with tobacco tissue culture. Physiol Plant 15:473-497

Park HG (2006) Genetical improvement of Brassica in Korea. Acta Hort. (ISHS) 706:31-48

Sasaki K, Nagahashi G, Gretz MR, Taylor IEP (1989) Use of per-C-deuterated myo-inositol for study of cell wall synthesis in germinating beans. Plant Physiol 90: 686-689

Schenck HR, Hoffmann F (1979) Callus and root regeneration from mesophyll protoplasts of basic Brassica species: $B$. campestris, B. oleracea and B. nigra. Z Pflanzenphysiol $82: 354-360$

Vatsya B, Bhaskaran S (1982) Plant regeneration from cotyledonary protoplasts of cauliflower (Brassica oleracea L. var botrytis L.) Protoplasma 113:161-163

Xu ZH, Davey MR, Cocking EC (1982) Plant regeneration from root protoplasts of Brassica. Plant Sci Lett 24:117-121

Yamagishi H, Nakagawa S (2004) Somatic hybrids between Arabidopsis thaliana and cabbage (Brassica oleracea). J Jpn Soc Hortic Sci 73:319-323 